\title{
THE FALLACY OF CUTTING TREES BEFORE THEY ARE MATURE
}

\author{
BY W. M. RoBERTSON
}

\author{
Anglo-Newfoundland Development Company, Grand Falls, Newfoundland
}

T IS generally conceded that it is not sound business practice to cut small immature trees.

It is not sound economically because the cost of cutting, piling, and otherwise handling large numbers of bolts per cord is abnormally high.

It is not sound silviculturally because the period of most rapid growth is during the polewood stage-from $4^{\prime \prime}$ to $8^{\prime \prime}$ in diameter. During the sap. ling stage a period of 30 to 50 years must elapse before a single foot of merchantable wood is available. During the succeeding 30 years the volume of wood increment multiplies at an astounding rate.

These concessions have been based largely on general observations and in consequence cutting of undersized trees is still common practice.

The purpose of this report is to present some factual data to illustrate the fallacy of such policy.

In Section I, analysis of the periodic growth rate of a typical dominant black spruce, and a typical dominant balsam fir, is given. These deductions are then applied in Section II to a normal stand table to illustrate the volume that may be reasonably expected to accrue in ten, twenty, and thirty years succeeding the sapling stage, under given forest conditions.

\section{SECTION I}

\section{Growth of Trees in Polewood Stage}

Hereunder is an analysis of the development of dominant black spruce and balsam fir trees by decades on a good site in Newfoundland. The com. putations and analysis are based on the following premises.

1. The form of Newfoundland spruce and fir conforms to the taper as given in taper and related tables contained in the Dominion Forest Service Form Class Volume Table Bulletin.

2. The local form class volume tables for Newfoundland, Cornus sitetype (1947) are applicable.

3. Germinated black spruce seedlings require fifteen years to reach breast height; balsam fir required ten years. These values have been derived from measurements taken in 1947. The D.F.S. values are fifteen years for each species.

4. Spruce and balsam germinate within one year after cutting or burn. As a matter of fact, the reproduction period is generally considered to be as much as fifteen years, depending upon seed supply and seed bed conditions. Any such additional reproduction period will increase the time required to reach the polewood stage.

5. Average dominant black spruce poles grow at the rate of 1.2 inches per decade; balsam fir at the rate of 1.4 inches per decade. Data collected in 1947 indicate that growth of these species is often much higher. 
6. The D.F.S. values in Form Class Volume Table Bulletin for bark thickness, and relation between diameter breast-height and diameter stump height, are accepted.

7. Length of bolts is taken as 48 inches; the height of stump, one foot; used top diameters are $3^{\prime \prime}$ and $2.5^{\prime \prime}$, presented in separate tables. Volumes are computed on inside bark measurements.

8. The converting factor of 82 cubic feet of solid wood per stacked cord is used. The D.F.S. value of 85 cubic feet is standard, but in the latter instance material over $8^{\prime \prime}$ D.B.H. is included in arriving at this higher value.

Based on the foregoing premises, it has been determined that the average dominant black spruce required 40 years to reach $3^{\prime \prime}$ D.B.H.; balsam fir, 28 years. The form or taper of the respective species at $3^{\prime \prime}$ and $4^{\prime \prime}$ and at diameters attained at each of the three succeeding decades thereafter are shown in graphs 1 and 2. From these graphs the number and dimensions of full 48-inch bolts at each of the several ages may be read.

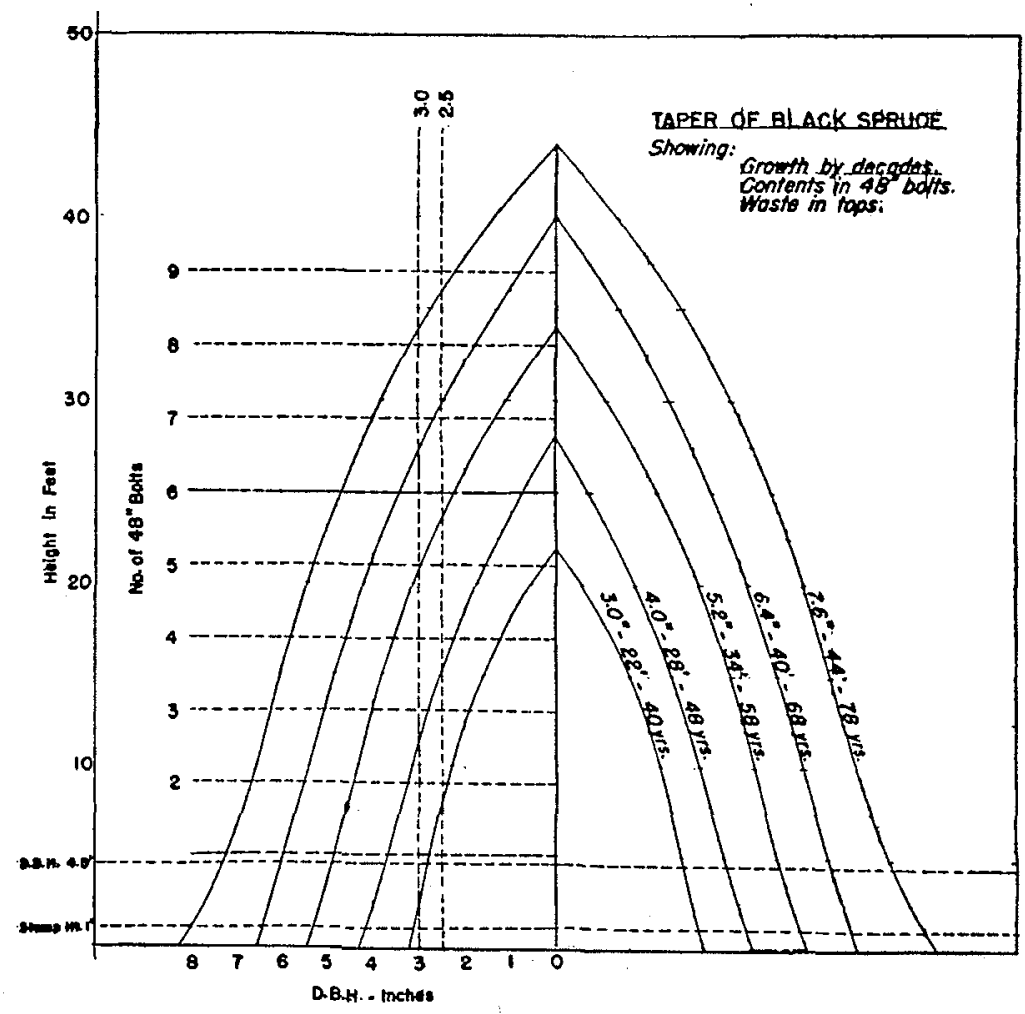


Although the volumes computed for these bolts were somewhat higher than volumes given in the standard volume tables (Tables No. 12 and No. 15), the latter values have been accepted. This was done to maintain consistent relationship between total and merchantable values, and to ensure conservative results in the deductions.

The deductions from the subsequent computations are summarized in Table No. 1.

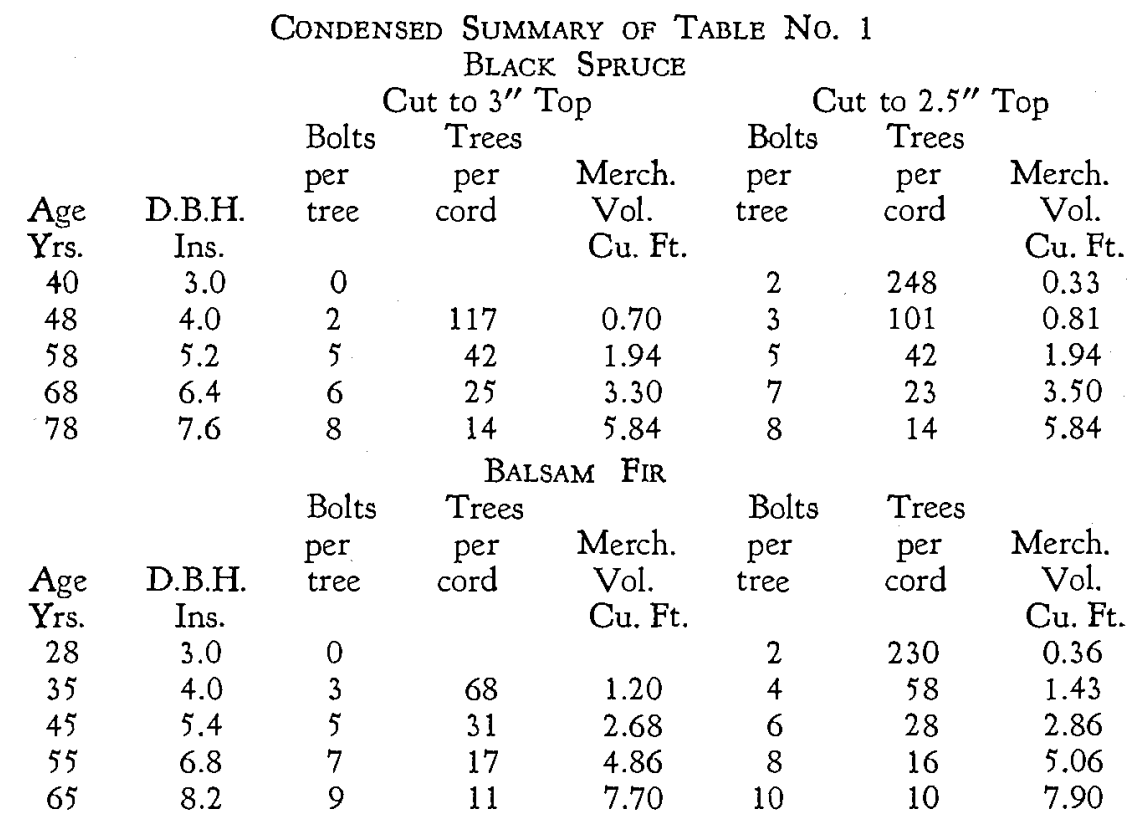

Black Spruce Cut to $3^{\prime \prime}$ Top (Table IA)

It is a self-evident truth that there can be no merchantable volume in a tree $3^{\prime \prime}$ D.B.H. O.B. when cutting is restricted to $3^{\prime \prime}$ D.I.B.

It may be seen from Graph 1 that a $4^{\prime \prime}$ black spruce (48 years old) will provide two small bolts with a volume of 0.70 cubic foot. At this rate it will require 117 trees ( 334 bolts) to provide one cord of 82 cubic feet. The remainder of the tree, stump and top waste, is 20 feet or 72 per cent of the total length and represents 30 per cent of the total volume.

If the tree is left to grow for another ten years, its diameter will be 5.2"; the bole will contain 5 bolts. The volume will be 1.94 cubic feet, and therefore not 117 trees, but 42 trees, about one-third the number, will produce a cord of wood. Waste in length will be reduced from 72 per cent to 41 per cent; in volume from 30 per cent to 10 per cent. Merchantable volume increased from $0.70 \mathrm{cu}$. ft. to $1.94 \mathrm{cu}$. ft. or 177 per cent.

Since, by reason of the taper of the tree, only one full additional bolt is available by the time the tree has reached $6.4^{\prime \prime}$, at 68 years of age increment is not so apparent. However, the 6 bolts are larger with a merchantable 
volume of $3.30 \mathrm{cu}$. ft. The periodic increment has grown from $1.24 \mathrm{cu}$. ft. to $1.36 \mathrm{cu}$. $\mathrm{ft}$. At this diameter, 25 trees will constitute a cord. There is no reduction in waste because an extra half bolt is included in the top.

Black spruce is probably mature at 80 years of age after which growth rate will decline. At the end of the third decade, at 78 years of age, it attains a diameter of 7.6" and provides 8 bolts, with a volume of $5.84 \mathrm{cu}$. ft. Thus the number of trees required per cord is further reduced to 14. All but 12 feet of the tree is utilized; the waste is reduced to 3 per cent of the total volume.

SLAL

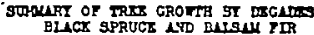

\begin{tabular}{|c|c|c|c|c|c|c|c|c|c|c|c|c|c|}
\hline \multirow{2}{*}{ Ienes } & DEQ & Be. & Bofts & $\begin{array}{l}\text { Treos } \\
\text { par } \\
\text { Cord }\end{array}$ & \multicolumn{2}{|c|}{$\begin{array}{c}\text { Meate } \\
\text { Longth } 6\end{array}$} & \multicolumn{3}{|c|}{ rotal folumesete fs } & $\begin{array}{l}\text { ver an: } \\
\text { volugis: }\end{array}$ & \multicolumn{3}{|c|}{ 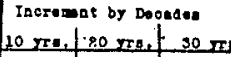 } \\
\hline & Incho: & Fent & & & seot & & ou.rt. & ou.5t. & & ou.58. & ou,ft. & ou.rt. & ou.tt. \\
\hline 10 & & 28 & 0 & - & - & - & 0.50 & - & - & & & & - \\
\hline$\omega$ & 4.0 & 20 & 2 & 112 & 20 & 72 & 1.00 & .30 & 30 & .70 & - & - & $=$ \\
\hline$\infty$ & 8.2 & 34 & $B$ & 42 & 14 & 41 & 2.18 & .21 & 10 & 1.94. & 1.24 & & \\
\hline$\infty$ & 8.4 & 10 & $B$ & 25 & 16 & 10 & 5.70 & (0). & 11 & 3.30 & 1.30 & 2,00 & \\
\hline 78 & 6 & 4 & B & 14 & 18 & 27 & 0.05 & .21 & 3 & 5.84 & 2,54 & soo & 5.14 \\
\hline & & & & & wer es & ves & so 2. & TOP & & & & & \\
\hline 10 & 3.0 & 2 & 8 & 248 & 14 & 63 & 0.50 & .17 & 34 & .35 & & & \\
\hline 40 & 6.0 & 20 & 5 & 101 & 16 & $\infty$ & 1.00 & .10 & 10 & .01 & & & \\
\hline$\infty$ & 5.1 & $\mathbf{s}$ & 5 & 42 & 16 & 41 & 2.15 & .21 & 10 & 1.24 & 1.13 & & \\
\hline$\infty$ & 6.4 & 10 & 7 & 83 & 22 & $\mathbf{0 0}$ & 3.70 & .80 & 8 & 3.50 & 258 & 2.08 & \\
\hline 70 & 7.6 & 4 & B & 14 & 18 & 27 & B.0B & .21 & 3 & 5.84 & 2.34 & 390 & 5.05 \\
\hline & & & & 0. & wan & $\mathrm{R}$ CU: & $03=5$ & & & & & & \\
\hline 28 & 3.0 & 83 & - & - & - & - & .05 & - & - & & & & \\
\hline so & 1.0 & 30 & 3 & $\infty$ & 10 & 80 & 1.01 & .22 & 25 & 2.20 & & & \\
\hline 45 & B.t & 37 & 5 & 31 & 17 & 46 & 2.02 & .20 & 7 & 2.08 & $1 \times 8$ & & \\
\hline S8 & 6.8 & 46 & 7 & 17 & 18 & 36 & 5.10 & .30 & ${ }^{\circ}$ & 4.86 & 218 & 300 & \\
\hline 80 & 8.2 & 30 & ${ }^{\circ}$ & 11 & 16 & 28 & 7.97 & .27 & 3 & 17.70 & 2.84 & 20 & 450 \\
\hline & & & & D - & IIsus & $\mathrm{B} C \mathrm{CD}$ & 02.54 & & & & & & \\
\hline 28 & 5.0 & 25 & 2 & 230 & 17 & 68 & .08 & .20 & 41 & .38 & & & \\
\hline 38 & 6.0 & so & 4 & 38 & 14 & 47 & 1.31 & .15 & 2 & 243 & - & & \\
\hline 45 & 3.4 & 37 & 0 & 28 & 13 & 35 & 2.92 & .20 & 2 & 280 & 2140 & & \\
\hline 58 & 0.0 & 46 & 8 & 16 & 12 & 27 & 5.18 & .18 & 3 & 5.06 & 226 & 3.72 & \\
\hline 68 & 8.2 & so & 10 & 10 & 10 & 20 & 7.07 & .15 & 2 & 7,80 & 2,94 & 5.10 & 0.58 \\
\hline
\end{tabular}

While it takes 48 years for black spruce to produce $0.70 \mathrm{cu}$. $\mathrm{ft}$. in the succeeding 20 years the volume is increased $2.60 \mathrm{cu}$. ft. or 370 per cent. In another ten years increment is further increased by $3.90 \mathrm{cu}$. $\mathrm{ft}$. or over seven times the volume obtainable from the 4 " tree.

Black Spruce Cut to 2.5" Top (Table IB)

The effect of more complete utilization of tops-cutting to 2.5 inches, is illustrated in Table IB. 
On this standard 2 bolts can be taken from a tree 3" D.B.H. O.B. The volume, $0.33 \mathrm{cu}$. $\mathrm{ft}$. is so small, however, that it requires the astounding number, 248 stems, to provide one stacked cord. The waste in tree length is 63 per cent, in volume 34 per cent. It is obvious that cutting to $3^{\prime \prime}$ D.B.H. is not economically feasible.

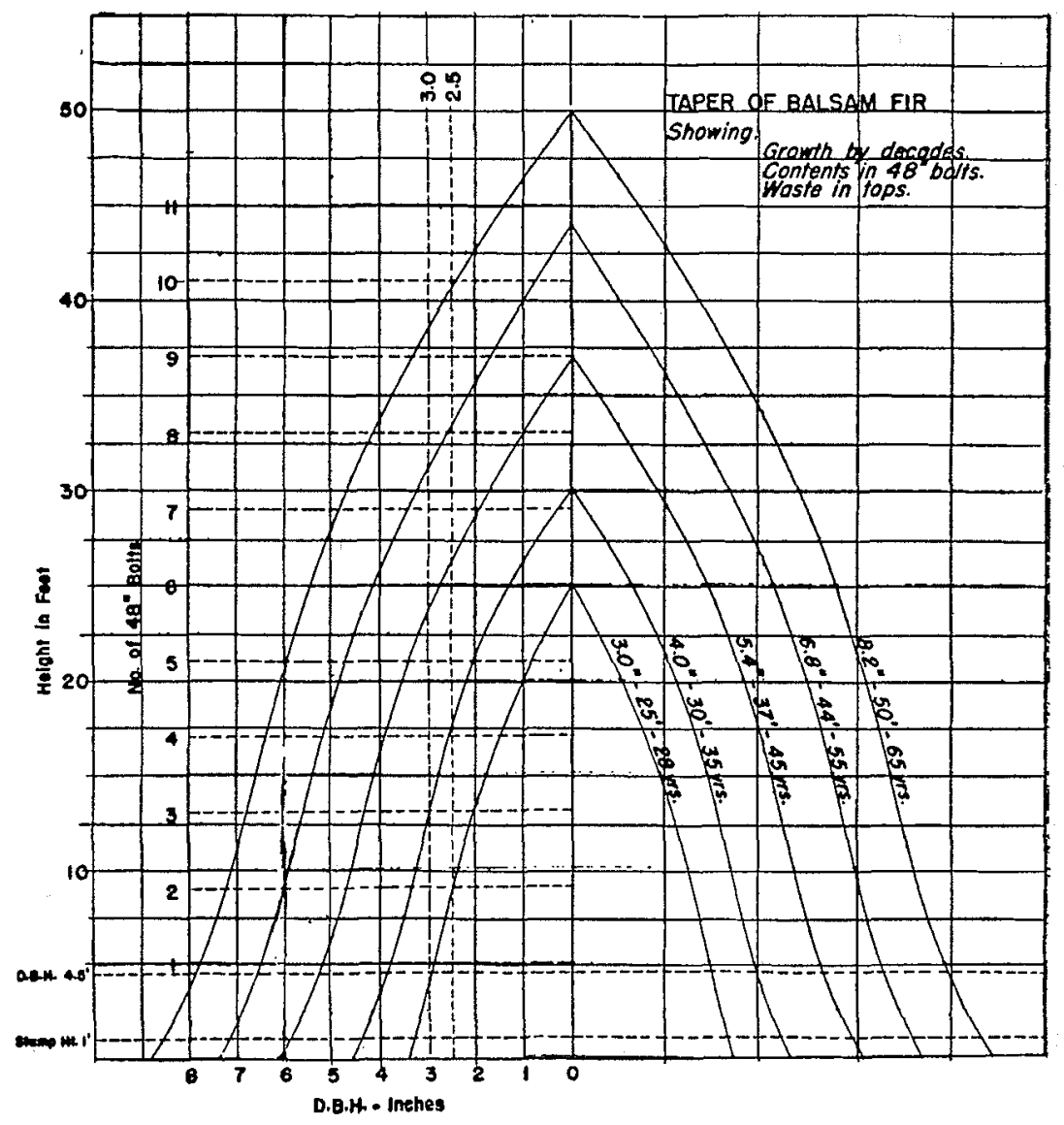

One extra bolt is obtainable from a 4 " tree by cutting to $2.5^{\prime \prime}$ instead of to 3". Thus the merchantable volume is increased from $70 \mathrm{cu}$. ft. ob. tained by the $3^{\prime \prime}$ limit to $81 \mathrm{cu}$. ft. The extra 13 per cent in volume should amply justify the additional cost involved in taking the additional bolt from the top. The number of trees per cord is thus reduced from 117 to 101 . Waste is reduced from 30 per cent to 19 per cent.

No additional bolts are obtainable from the $5.2^{\prime \prime}$ tree, age 58 years, by cutting to the lower diameter limit. 
But the 6.4" tree, at 68 years of age, gives one extra bolt, thus increasing the volume from $3.30 \mathrm{cu}$. ft. to $3.50 \mathrm{cu}$. ft., and hence 23 trees instead of 25 will provide a cord of wood. The wastage is reduced from 11 to 6 per cent.

The mature tree, 7.6" D.B.H., will not produce more bolts under the reduced diameter limit.

It may be concluded, therefore, that on the whole the saving by cutting to $2.5^{\prime \prime}$ instead of $3.0^{\prime \prime}$ is not very significant.

Balsam Fir Cut to $3^{\prime \prime}$ Top (Table IC)

Newfoundland balsam fir grows more rapidly than black spruce. The rotation ages are probably 60 years and 80 years respectively. On the better site-types fir attains 3 " D.B.H. in 28 years. Thereafter average growth rate is 1.4 inches per decade until it reaches maturity. It has better diameter. height growth than black spruce, and consequently volumes are higher.

At 4" D.B.H. (35 years), Graph 2 shows that there are three bolts ob. tainable. Thus, with a volume of $1.20 \mathrm{cu}$. ft. 67 trees will provide a stacked cord. Sixty per cent of the tree length, which constitutes 15 per cent of the volume, is left in the woods.

Undisturbed for one decade, when the tree will be 45 years old with diameter of 5.4" D.B.H., it will yield five bolts with volume of $2.72 \mathrm{cu}$. ft. Then instead of 67 trees, 30 trees will provide a cord of wood. The top length will be reduced to 46 per cent of total length; the volume waste will be only 7 per cent. Volume increment for the decade will be $1.52 \mathrm{cu}$. ft. or 126 per cent greater than the volume obtainable from the 4 " tree.

When the tree attains a diameter of $6.8^{\prime \prime}$ at 55 years of age, there will be 7 bolts, sufficient to produce $4.86 \mathrm{cu}$. $\mathrm{ft}$. or a further increase of $214 \mathrm{cu}$. $\mathrm{ft}$. The increment for the 20-year period will have accumulated to $366 \mathrm{cu}$. $\mathrm{ft}$. or 300 per cent of the volume of the $4^{\prime \prime}$ tree. The number of stems per cord will be reduced from 67 to 17 . Waste in volume will be only 6 per cent.

At maturity the tree will be $8.2^{\prime \prime}$ D.B.H. and will provide 9 bolts. The merchantable volume will then be $7.70 \mathrm{cu}$. $\mathrm{ft}$., more than 6 times greater than will be available at 35 years of age. Eleven trees will constitute a cord. Wastage will be reduced to 3 per cent of the total volume.

It is questionable whether it pays to cut as many as 67 trees per cord. Certainly it is unsound, silviculturally, to cut balsam fir under 60 years of age.

Balsam Fir Cut to 2.5" Top (Table ID)

As with spruce, two bolts can be obtained from a 3 -inch tree by cutting to $2.5^{\prime \prime}$ D.B.H. However, the volume is only 0.36 cut. ft. and therefore 230 stems must be handled to produce one cord of wood. Their utilization cannot be justified even for thinning operations.

One extra bolt is obtainable from each of the other diameter classes by cutting to $2.5^{\prime \prime}$ instead of 3 " D.B.H. This means that the number of trees per cord will be reduced from 68 to 58,31 to 28,17 to 16 , and 11 to 10 in the 4", 5", 7" and $8^{\prime \prime}$ diameter classes respectively, with corresponding reduction in wastage.

The average increase in volume obtained is approximately 0.8 per cent. It is questionable whether the increased costs involved in salvaging this small additional volume justifies utilization to the lower limit. 


\section{SECTION II}

Growth of a Stand in Polewood Stage (Table 2)

It is difficult to visualize the foregoing facts fully when restricted to a single tree. That they may be more fully assessed the deductions are now applied to an actual stand table to illustrate the periodic increment and yield that may accrue on such a stand if left for 10,20 , or 30 years beyond the sapling stage, at 45 years of age.

It is not suggested that the values given hereunder represent the growth rate and yield of the average, undisturbed stand. They do, however, indicate the possibilities of a well managed stand on a good site. More particularly, they illustrate the error of cutting immature timber. If the growth were slower, the need for delayed cutting would be correspondingly greater.

Again the analysis is based on certain premises.

1. The stand is young and even-aged.

The trees concerned are all dominants, and being young, will survive for 30 years. Any possible losses from mortality will be fully replaced by dominant trees of other species, notably white spruce.

2. Few, if any of the undersized saplings now suppressed will survive or enter the main stand until the dominant trees are removed.

3. The increment rates are those used in the foregoing analysis, namely, $1.2^{\prime \prime}$ per decade for black spruce, and $1.4^{\prime \prime}$ per decade for balsam fir.

4. The utilization factors are one-foot stump and 3 -inch top, the factors upon which the volume tables are based.

Computations are summarized in Table No. 2

The stand selected is that for growth sample plot No. 8, 1947 survey. It represents an average, young mixedwood stand on the Cornus or best-site type. It is 45 years of age, having followed a fire of 1900 .

It contains 1670 trees per acre with a stand density of 334 units, equiv. alent to about 75 per cent of a fully stocked stand. Hence there is ample growing space for the dominant trees.

In addition to the 350 dominant black spruce and balsam fir concerned, there are a few large white spruce and many small white birch and poplar.

Black Spruce Cut to 3" Top

At 45 years of age 65 trees, or one-half of the spruce stand, are still in the 3 -inch sapling class and therefore have no merchantable volume. The remaining 65 trees have a volume of only 75.5 cubic feet or less than a cord of wood. Obviously then spruce cannot be cut at 45 years of age.

In ten years the saplings will enter the 4 -inch polewood class and will have a volume of $58.5 \mathrm{cu}$. $\mathrm{ft}$. In the meantime, the 4-inch and 5 -inch poles will have grown to 162.5 cubic feet. The total volume will be 2.7 cords, or three times that in the stand at 45 years of age. The growth rate during the decade will be 14.5 cubic feet per year/acre, a rate of 9.8 per cent (Pressler's increment). This volume, however, is still not sufficient to justify cutting.

By the end of the second decade the volume will have increased to 5.1 cords, almost double that available at 55 years of age. The growth rate, too, will increase to 19.7 cubic feet per year/acre, a rate of 6.2 per cent. 
Economically it might be considered profitable to cut a stand of five cords per acre. However, for silvicultural reasons, while growth rate is still more than 5 per cent, cutting would not be warranted.

When the stand approaches maturity, at 75 years of age, the situation will change. There will then be 8.1 cords per year/acre. The volume increment will be $24.6 \mathrm{cu}$. ft. per year/acre, but the percentage rate will have declined to 4.5 per cent. For silvicultural reasons, then, young black spruce should not be cut under 75 years of age when the average diameter will be over 7 inches.

Balsam Fir Cut to 3" Top

Although there are 50 more spruce than fir in this stand, by reason of the more rapid growth of the latter species most of the spruce are suppressed and in the lower sapling classes, while three-quarters of the fir are in the dominant positions. Furthermore, of the 220 of these dominant balsam fir, two-thirds of them are already in the $4 "$ and $5^{\prime \prime}$ polewood classes and producing merchantable wood. Although the average diameter is still only 4.0", they contain 3.1 cords of wood.

Ten years hence, at 55 years, the entire stand will be in production to the extent of 7.5 cords. The periodic growth rate will be $36.0 \mathrm{cu}$. ft., or 8.3 per cent per year acre. The operator may be tempted to cut such a stand even although the average diameter is only 5.4". That this would be a mistake may be seen from examination of the stand at 65 years of age.

By 65 years of age the average diameter will be $6.8^{\prime \prime}$. The volume will have almost doubled again during the decade to 13.3 cords. The rate is still well above 5 per cent.

At 75 years of age, if decay has not caused serious mortality or cull, a volume of 21 cords may be expected. The increment rate will have reached the surprising value of $62 \mathrm{cu}$. ft. per year/acre. However, the percentage rate will have dropped to 4.4. It seems probable, therefore, that the bal. sam has then reached or passed its silvicultural rotation age. It would seem then that for maximum volume production fir should not be cut under 70 years of age, when the average diameter is 8 inches.

Combined Species

At 45 years of age, 350 trees will produce only 4 cords per acre.

Ten years later the volume will have increased to over 10 cords from trees of $5.2^{\prime \prime}$ average diameter.

By 65 years of age, the stand will be over 18 cords per acre, growing at a rate of $67.7 \mathrm{cu}$. ft. per year/acre.

At maturity, 75 years, a volume of 29 cords per acre may reasonably be expected, when it will be producing more than a cord per year.

It may be concluded then that 40 years must elapse after fire or clear. cutting before one foot of wood is available. Fifteen years later there will be 10 cords. At 65 years the volume will have increased to 18 cords. The final 10 years to attain 75 years of age will result in a stand of 29 cords. For maximum production of young forests, wood should not be cut under 7" D.B.H.

Can there be any question that it is fallacy to cut immature stands? 


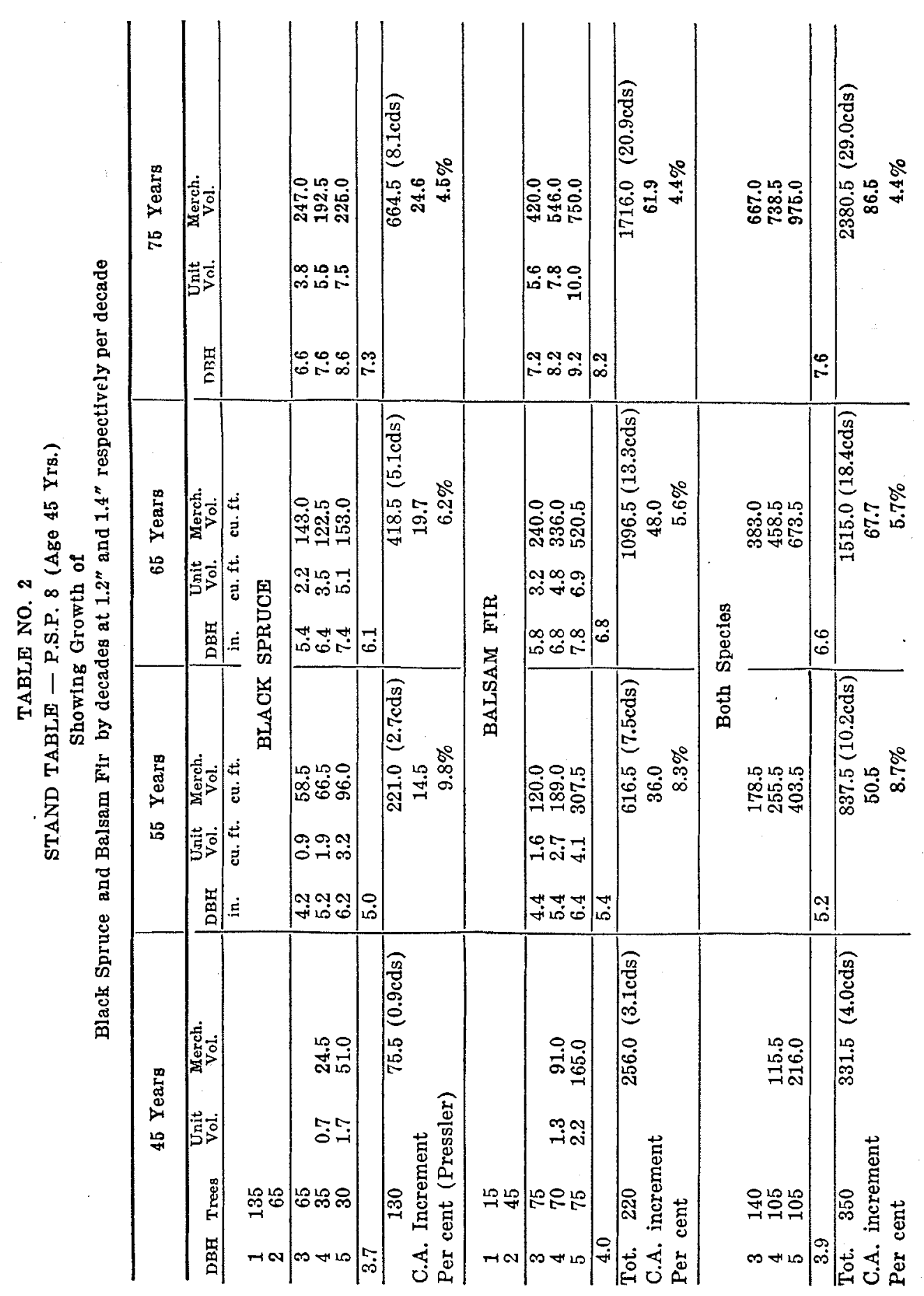

